\title{
ARTIGO \\ A CULTURA DE SEGURANÇA DE ALIMENTOS E OS ELEMENTOS DE MENSURAÇÃO: REVISÃO DE BIBLIOGRAFIA
}

\section{A CULTURA DE SEGURANÇA DE ALIMENTOS E OS ELEMENTOS DE MENSURAÇÃO: REVISÃO DE BIBLIOGRAFIA}

\begin{abstract}
Victor Chiaroni Galvão'
Mestre em Ciências pelo Departamento de Medicina Veterinária Preventiva e Saúde Animal Faculdade de Medicina Veterinária e Zootecnia da Universidade de São Paulo, São Paulo, Brasil https://orcid.org/0000-0003-1293-7119

vchiaroni@gmail.com

Simone de Carvalho Balian ${ }^{2}$

Prof ${ }^{\mathrm{a}}$.Dr ${ }^{\mathrm{a}}$. Livre Docente pelo Departamento de Medicina Veterinária Preventiva e Saúde Animal Faculdade de Medicina Veterinária e Zootecnia da Universidade de São Paulo, São Paulo, Brasil https://orcid.org/0000-0002-2211-9315

\section{balian@usp.br}

1 Participou ativamente da redação e elaboração do artigo, discussão dos resultados, revisão e aprovação da versão final do trabalho.

2 Participou ativamente da discussão dos resultados, revisão e aprovação da versão final do trabalho.

\section{RESUMO}

Ao longo do tempo foram desenvolvidos controles sobre os alimentos e seus processos a fim de torná-los seguros para 0 consumo humano. Os esforços para este fim, porém, não foram suficientes, tendo em vista o crescente número de casos de doenças alimentares. Pesquisadores identificaram e adaptaram conceitos derivados das ciências sociais, utilizando-os na segurança dos alimentos, criando assim diversas concepções de Cultura de Segurança dos Alimentos (CSA). Sabe-se atualmente que a CSA influencia a inocuidade dos alimentos e é considerada um importante fator de risco a ser administrado pelas organizações. $O$ presente estudo teve por objetivo apresentar e analisar conceitos de CSA, seus autores e os elementos/fatores que os compõem. Também abordou os processos de desenvolvimento, avaliação e amadurecimento da CSA em estabelecimentos que manipulam alimentos no Brasil ou em todo o mundo. Foram identificados dezoito trabalhos que apresentaram diferentes fatores de CSA e quatro que aplicaram instrumentos de CSA no Brasil. Constatou-se que a utilização de ferramentas para caracterizar a CSA vem se aprimorando ao longo do tempo. Os autores mais recentes utilizam, frequentemente, abordagem mista de métodos de avaliação para tal finalidade. Concluindo, propõe-se neste trabalho um conceito mais refinado de CSA em relação aos já existentes e um novo elemento/fator para caracterizar a CSA nos estabelecimentos que manipulam alimentos no Brasil.

Palavras-chave: Alimentos seguros Prevenção. Controle. 


\section{ABSTRACT}

Over time, controls on food and its processes have been developed in order to make them safe for human consumption. However, efforts to this end were not sufficient, in view of the growing number of cases of foodborne illnesses. Researchers have identified and adapted concepts derived from the social sciences using them in food safety, thus creating different concepts of Food Safety Culture (FSC). It is currently known that FSC influences food safety and is considered an important risk factor to be managed by organizations. This study aimed to present and analyze FSC concepts, their authors and the elements/factors that compose them. It also addressed FSC development, evaluation and maturation processes in establishments that handle food in Brazil or around the world. Eighteen studies were identified that presented different FSC factors and four that applied FSC instruments in Brazil. It was found that the use of tools to characterize FSC has been improving over time. More recent authors often use a methods mixed approach to assessment for this purpose. In conclusion, this work proposes a more refined concept of FSC in relation to the existing ones and a new element/factor to characterize FSC in establishments that handle food in Brazil.

Keywords: Food Safety. Prevention. Control.

\section{INTRODUÇÃO}

Em 1857, Pasteur inaugurava a área das ciências que teve os micro-organismos como objeto. Em 1880, Gärtner isolou Salmonella spp. de alimentos, agente até os dias atuais altamente importante na ocorrência de surtos de doença de origem alimentar. Iniciou-se na época a chamada Era de Ouro da microbiologia, atuando significativamente no desenvolvimento da Segurança dos Alimentos (SA). Vários autores divulgaram estudos sobre identificação de patógenos em alimentos causadores das Doenças Alimentares (DA) e as formas de controlá-las, principalmente por meio de técnicas, utilizando processos térmicos, como a temperatura (ex: pasteurização) e realizando análises microbiológicas no produto acabado. Ao longo do tempo, as práticas preventivas ganharam destaque agindo de forma a evitar contaminação, multiplicação de agentes patogênicos ou mesmo a sua sobrevivência durante os processos de fabricação de alimentos (GRIFFITH, 2006). Com isso surgiram, na década de 90 , os Sistemas de Gestão de Segurança dos Alimentos, conhecidos internacionalmente pela sigla FSMS (Food Safety Management System), como as Boas Práticas de Fabricação (BPF) e a Análise de Perigos e Pontos Críticos de Controle (APPCC), que logo foram incorporadas nas legislações sanitárias (GRIFFITH, 2006). Mesmo assim, os sistemas de gestão, as legislações e os avanços da microbiologia aplicada ainda não foram suficientes para reduzir os casos das Doenças Alimentares, como demostrado em estudos recentes (BRASIL, 2019; EUROPEAN FOOD SAFETY AUTHORITY, 2018; CENTERS FOR DISEASE CONTROL, 2017). Ficou patente que os controles sobre os alimentos 
determinaram como os processos devem ser realizados, porém não são capazes de assegurar como as pessoas devem realizálos. Falta aqui compreender e interferir, de forma efetiva, na Cultura de Segurança dos Alimentos (CSA). A CSA foi considerada um novo fator de risco para a Segurança dos Alimentos (GRIFFITH, LIVESEY e CLAYTON, 2010a).

É sob esse contexto que este estudo foi desenvolvido, apresentando uma revisão de literatura sobre a Cultura de Segurança dos Alimentos (CSA), destacando elementos e fatores de caracterização e avaliação.

\section{METODOLOGIA}

Utilizou-se para o levantamento de literatura a palavra-chave Cultura de Segurança de Alimentos (em inglês Food Safety Culture). Foram utilizadas bases de dados nacionais (ex.: LILACS, SciELO e Periódicos CAPES) e internacionais. $\mathrm{Na}$ base de dados Sciencedirect foram encontrados 187 trabalhos, na Pubmed 14 artigos e na Emerald Insight 25 estudos. Foram critérios de inclusão de artigos, a presença do conceito de CSA, dos fatores ou elementos que compõem a CSA e também a utilização de um questionário para a avaliação da CSA em organizações. Foram utilizados dois meses para a compilação dos trabalhos. Os trabalhos estavam incluídos em um período de doze anos, ou seja, entre 2009 e 2021. A maioria dos trabalhos utilizaram questionários para identificar os elementos que compõem a CSA. $\mathrm{Na}$ continuidade do texto a palavra questionário será substituída por instrumento ou ferramenta.

\section{CONCEITO DE CULTURA DE SEGURANÇA DE ALIMENTOS E AUTORES}

Segundo Yiannas (2009), um dos pioneiros a definir o conceito, a CSA foi estruturada a partir dos pensamentos, atitudes, crenças e comportamentos das pessoas que se relacionam em um ambiente de produção de alimentos. Trata-se de um dinâmico processo de influências e interferências de naturezas individuais e coletivas. Cada colaborador possui uma parcela de responsabilidade sobre a CSA impactando positiva ou negativamente sobre a inocuidade do alimento. Os esforços de cada colaborador, alinhado a um propósito único de produzir e manter o alimento seguro, geraram resultados mais promissores do que o empenho isolado de cada indivíduo, pois os pensamentos, atitudes e comportamentos, quando alinhados e compartilhados em sinergismo, alcançaram resultados superiores e efetivos. Para Yiannas (2009), a CSA foi considerada o modo como fazem as coisas, 
ou seja, o modo como a organização pratica a Segurança dos Alimentos. Griffith, Livesey e Clayton (2010a) definiram a CSA como a agregação de atitudes, valores e crenças predominantes, relativamente constantes, aprendidas e compartilhadas, que contribuem para os comportamentos de higiene usados em um ambiente específico de manipulação de alimentos. Para Powell, Jacob e Chapman (2011) tratou-se de um conjunto de valores, crenças e comportamentos comumente compartilhados relacionados à segurança de alimentos, enquanto para Sarter e Sarter (2012) foi uma forma pela qual uma organização ou grupo de pessoas atinge o nível de segurança dos alimentos em suas mentes e comportamentos. Seward, Bobmeier e Baron (2012) defenderam que uma forte CSA é bastante útil para guiar as decisões do cotidiano, as ações e os comportamentos, permitindo assim uma produção mais segura. Taylor (2011) e Taylor et al. (2015) relataram que a CSA na indústria compreende atitudes, valores e práticas predominantes relacionados à segurança dos alimentos que são ensinados, direta e indiretamente, aos novos funcionários. Wright, Leach e Palmer (2012) e Abidin (2013) desenvolveram instrumentos de mensuração de CSA baseando-se nos fatores determinados por Griffth, Livesey e Clayton (2010b). Jespersen et al. (2016) inspiraram-se nos trabalhos de Wright, Leach e Palmer
(2012), Griffth, Livesey e Clayton (2010b), De Boeck et al. (2015) e Taylor et al. (2015) para elaborarem um instrumento de avaliação de CSA. Para outros autores, apesar da existência da CSA nas organizações, acreditaram que esta não pode ser mensurada (BALL, WILCOCK e COLWELL 2010; NEAL, BINKLEY, HENROID, 2012; DE BOECK et al, 2015). Defenderam a realização de estudos sobre Clima de SA, os quais possibilitaram identificar ou reconhecer a CSA, isto é, captar as percepções dos colaboradores, o contexto em que a empresa está operando e da análise do seu Sistema de Gestão de Segurança de Alimentos para, a partir daí, identificar na Cultura Organizacional da empresa o modus operandi da Segurança de Alimentos. A Global Food Safety Initiative's (GLOBAL FOOD SAFETY INITIATIVE, 2018) definiu a CSA como o conjunto de valores, crenças e normas compartilhadas que afetaram a mentalidade e o comportamento em relação à segurança dos alimentos em toda a organização. Esta definição é bastante prática e relaciona de forma aplicada elementos da Cultura Organizacional e da Segurança de Alimentos em uma organização.

Recentemente, Sharman, Wallace e Jespersen (2020) revisaram as terminologias e as diferentes compreensões de Cultura e Clima de Segurança de Alimentos e propuseram definições distintas. Entende 
Cultura de Segurança de Alimentos como um construto de longo prazo existente no nível organizacional relacionado às crenças, comportamentos e premissas profundamente enraizadas que são aprendidas e compartilhadas por todos os colaboradores, que impactam o desempenho da segurança dos alimentos da organização, enquanto que Clima de Segurança de Alimentos define um construto temporário existente a nível individual, relacionado com a percepção e atitudes dos indivíduos e como influenciam outros numa organização a aderir aos Sistemas de Gestão da Segurança dos Alimentos e aplicá-los de forma prática no seu ambiente de trabalho.

Considerando as definições abordadas, conhecer, construir e liderar a CSA tem sido cada vez mais reconhecida como uma ferramenta com significativo potencial de contribuir para a redução do risco da ocorrência de Doenças Alimentares em organizações alimentícias.

A seguir são demonstrados no Quadro 1 os autores e suas respectivas abordagens sobre CSA, destacando-se os elementos que consideram de maior influência e significado para a sua estruturação, sendo esses os elementos que serviram de base para a construção de ferramentas de estudo da CSA. 
Quadro 1 - Fatores de Cultura de Segurança de Alimentos, de acordo com diferentes autores, ano de publicação, contexto e área adaptada ou instrumento, São Paulo/ 2021.

\begin{tabular}{|c|c|c|c|c|c|}
\hline $\begin{array}{l}\text { Autor/ ano } \\
\text { publicação }\end{array}$ & $\begin{array}{l}\text { País de } \\
\text { origem da } \\
\text { pesquisa }\end{array}$ & Contexto & $\begin{array}{l}\text { Área adaptada/ } \\
\text { instrumento }\end{array}$ & $\begin{array}{l}\text { Elementos de Cultura de } \\
\text { Segurança de Alimentos }\end{array}$ & Descrição dos Elementos de Cultura de Segurança de Alimentos \\
\hline \multirow[t]{5}{*}{$\begin{array}{l}\text { Yiannas } \\
\text { (2009) }\end{array}$} & \multirow[t]{5}{*}{$\begin{array}{l}\text { Estados } \\
\text { Unidos }\end{array}$} & \multirow[t]{5}{*}{$\begin{array}{l}\text { Varejo e } \\
\text { Indústria } \\
\text { "Food service" }\end{array}$} & \multirow[t]{5}{*}{$\begin{array}{l}\text { Cultura } \\
\text { Segurança }\end{array}$} & (I) Liderança & $\begin{array}{l}\text { Distinguiu o gerenciamento da liderança em Segurança dos Alimentos } \\
\text { e destacou o papel dos líderes em influenciar os outros e liderar o } \\
\text { caminho para o manuseio seguro de alimentos }\end{array}$ \\
\hline & & & & (II) Confiança dos colaboradores & $\begin{array}{l}\text { A confiança deve ser conquistada dentro da organização, entre os } \\
\text { colaboradores e deve ser mantida e reforçada através do diálogo } \\
\text { constante }\end{array}$ \\
\hline & & & & (III) Apoio à gestão & $\begin{array}{l}\text { Os colaboradores devem apoiar a gestão e a liderança, fomentando a } \\
\text { Cultura de Segurança de Alimentos, impactando positivamente a } \\
\text { segurança dos alimentos }\end{array}$ \\
\hline & & & & (IV) Responsabilidade & $\begin{array}{l}\text { Esclarecer aos colaboradores o que se espera deles para a obtenção } \\
\text { de alimentos seguros e quais as consequências de uma boa e de uma } \\
\text { má prática na manipulação dos alimentos }\end{array}$ \\
\hline & & & & $\begin{array}{l}\text { (V) Compartilhamento de } \\
\text { conhecimento e informação. }\end{array}$ & $\begin{array}{l}\text { Manter constante a transmissão de mensagens, informações e } \\
\text { incentivos para as práticas corretas, utilizando diversas formas e } \\
\text { recursos de comunicação }\end{array}$ \\
\hline \multirow[t]{3}{*}{$\begin{array}{l}\text { Griffith, } \\
\text { Livesey } \\
\text { Clayton } \\
\text { (2010b) }\end{array}$} & \multirow[t]{3}{*}{ Reino Unido } & \multirow[t]{3}{*}{$\begin{array}{l}\text { Indústria de } \\
\text { Alimentos }\end{array}$} & \multirow[t]{3}{*}{$\begin{array}{l}\text { Cultura } \\
\text { Segurança }\end{array}$} & (I) Estilo e sistemas de gestão & $\begin{array}{l}\text { Abrangendo as percepções dos colaboradores em relação ao estilo e } \\
\text { sistema de gestão adotados interferem nas decisões voltadas ao } \\
\text { controle da Segurança dos Alimentos. Existência de procedimentos } \\
\text { documentados, os comportamentos praticados e o envolvimento da } \\
\text { administração nas operações diárias }\end{array}$ \\
\hline & & & & (II) Liderança & $\begin{array}{l}\text { Este fator identifica se as equipes são alavancadas pelo(s) seu(s) } \\
\text { líder(es) para executar e cumprir os padrões de Segurança dos } \\
\text { Alimentos dos negócios }\end{array}$ \\
\hline & & & & (III) Comunicação & $\begin{array}{l}\text { Avalia o fluxo de comunicação é multidirecional, de cima para baixo, } \\
\text { de baixo para cima (vertical) e entre os colaboradores (horizontal) sua } \\
\text { qualidade, isto é, clara, objetiva, direta e assertiva }\end{array}$ \\
\hline
\end{tabular}

Revista Higiene Alimentar, 36 (294): Jan/Jun, 2022

ISSN 2675-0260 - DOI: 10.37585/HA2022.01cultura 
(IV) Compromisso

(V) Ambiente

(VI) Percepção/ consciência/ comportamento de risco

$\begin{array}{llllll}\text { Ball, } & \text { Canadá } & \text { Indústria de } & \text { Instrumento de } & \text { (I) Comprometimento da unidade } \\ \text { Wilcock e } & \text { Processament } & \text { Clima } & \text { de } & \text { de trabalho } \\ \text { Colwell } & & \text { o de Carnes } & \begin{array}{l}\text { Segurança } \\ \text { de }\end{array} & \\ (2010) & & \text { Alimentos } & & \\ & & & \text { (II) Compreensão pessoal }\end{array}$

(II) Compreensão pessoal

(III) Treinamento em segurança dos alimentos

(IV) Comprometimento
gestão
Se estabelece quando se alinham valores e crenças da organização com aqueles dos seus colaboradores, direcionados à Segurança dos Alimentos. Os valores associados às recompensas, aos papéis, à satisfação no trabalho e ao empoderamento são subcomponentes do compromisso percebido

Compreende estruturas e processos organizacionais visíveis que caracterizam as dimensões internas do negócio. Fatores tangíveis, complacência, padrões, grau de excelência, consistência e suporte organizacional são elementos relevantes no suporte ao ambiente percebido pelos colaboradores

Compreendem as evidencias que explicitam a percepção dos colaboradores sobre comportamentos de risco de contaminação dos produtos. Também envolve a disposição dos trabalhadores, humor, "feedback" de desempenho, confiança e estratégia de comunicação de risco

Relacionado ao engajamento dos trabalhadores. Deve-se atentar para o comprometimento do líder ou supervisor da unidade, pois este exerce forte influência. É importante que o líder mantenha comunicação clara, constante e focada na Segurança dos Alimentos Os manipuladores devem ter clara compreensão do papel que desempenham na organização, sua importância e a influência que exercem sobre a Segurança dos Alimentos com suas práticas, desde as mais simples até as mais complexas

Capacitação e treinamentos devem ser contínuos, para aqueles que já trabalham na empresa e para todos aqueles que nela ingressam. Através deste elemento é possível assegurar o cumprimento do anterior da A gestão administrativa da organização demonstra que está comprometida com a Segurança dos Alimentos por meio de suas ações gerencias, seus líderes e do suporte ambiental com equipamentos, utensílios e demais recursos necessários para toda a organização

Revista Higiene Alimentar, 36 (294): Jan/Jun, 2022

ISSN 2675-0260 - DOI: 10.37585/HA2022.01cultura 


\section{(V) Infraestrutura}

(VI) Comportamento segurança de alimentos

\begin{tabular}{lllll}
\hline Neal, & Estados & Restaurante & Instrumento & de \\
Binkley e & Clima & de \\
Henroid & & & Segurança & de \\
(2012) & & Alimentos & \\
& & & \\
& & &
\end{tabular}

\begin{tabular}{lllll}
\hline Wright, & Reino Unido & Micro e & Instrumento & de \\
Leach e & & pequenas & Cultura & de \\
Palmer. & & empresas & Segurança & de \\
(2012) & & & Alimentos &
\end{tabular}

(I) Comprometimento da gestão

\section{de} de

(II) - Comportamentos (II) Couranca de alimentos colaboradores

(I) Prioidades

de (I) Prioridades e atitudes em relação a higiene dos alimentos

de
Relaciona-se ao grau de ajuste e conformidade do Sistema de Gestão de Segurança dos Alimentos e suas ferramentas (BPF, APPCC, etc) e os resultados esperados para a segurança dos alimentos

de Demonstrações de comportamentos positivos ou negativos em relação à Segurança dos Alimentos

Fundamental a gestão administrativa da organização demonstrar comprometimento com a Segurança dos Alimentos por meio de ações gerencias, seus líderes e do suporte ambiental (equipamentos, utensílios, etc.)

Evidência de comportamentos positivos ou negativos em relação à Segurança de Alimentos

A higiene alimentar é uma das principais prioridades, um fator crítico de sucesso empresarial e deve ser excelente de risco em higiene dos aos negócios, a ocorrência de incidentes envolvendo seus produtos alimentos

(III) Confiança da empresa nos A organização acredita que as ferramentas de autocontrole de pré-requisitos em segurança dos processos e produtos, como o sistema APPCC, são úteis e eficazes alimentos

(IV) Propriedade empresarial A organização é proativa na melhoria constante nas práticas e sobre higiene dos alimentos procedimentos de higiene dos alimentos. Considera essa temática um fator de risco para os negócios

(V) Competência, Mantém atualização constante no treinamento e capacitação de

aprendizagem, treinamento, pessoal nos temas relacionados à higiene dos alimentos, envolvendo conhecimento todos os colaboradores

(VI) Liderança em higiene dos A organização incentiva, reconhece e apoia a todos na adoção de alimentos

(VII) Envolvimento procedimentos de higiene alimentar, explica por que isso é necessário e parabeniza as boas práticas

colaboradores na revisão e sobre como melhorar a higiene alimenta desenvolvimento de práticas de higiene dos alimentos

Revista Higiene Alimentar, 36 (294): Jan/Jun, 2022

ISSN 2675-0260 - DOI: 10.37585/HA2022.01cultura 


\section{divienter Nimentar}

\begin{tabular}{llllll}
\hline Seward, & Estados & Indústria de & Instrumento & de & (I) Cultivar \\
Bobmeier e & Unidos & alimentos & Cultura & de & \\
Baron & & Segurança & de & \\
$(2012)$ & & Alimentos & (II) Educar & col
\end{tabular}

(VIII) Comunicação e confiança para se envolver em higiene dos alimentos e questões de registro

(III) Investigar

(IV) Elevar e melhorar

\begin{tabular}{llllll}
\hline Abidin & Estados & "Food service" & Instrumento de & (I) Apoio dos gerentes e \\
$(2013)$ & Unidos & em hospitais e & Cultura & de colaboradores & \\
& & escolas & Segurança de & (II) Comunicação & \\
& & Alimentos & & \\
& & & &
\end{tabular}

(III) Autocomprometimento

(IV) Suporte do ambiente

(V) Pressão no trabalho

(VI) Julgamento baseado risco
Mantém-se liberdade de expressão entre os colaboradores, para relatar problemas e sugerir melhorias

O líder é responsável por estimular, comunicar e desenvolver comprometimento para com os objetivos estabelecidos em Segurança dos Alimentos

Assegurar que todos na empresa conheçam e disponham das habilidades necessárias para cumprir práticas em Segurança dos Alimentos

Manter proatividade para identificar falhas, problemas, incongruências e más práticas. Ao mesmo tempo, manter-se atualizado perante os avanços científicos e industriais úteis e válidos para incrementar a Segurança dos Alimentos

As falhas do sistema são levadas a sério e são usadas como oportunidades de melhoria contínua

Esforços da gerência e colaboradores, adotando políticas voltadas à Segurança dos Alimentos

Avalia as percepções dos funcionários em relação à qualidade da comunicação e dos conhecimentos sobre Segurança dos Alimentos entre a gerência, a equipe supervisora e os manipuladores de alimentos

Avalia se as percepções dos funcionários em relação aos valores e crenças sobre Segurança dos Alimentos estão alinhadas com aqueles da organização

Avalia as percepções dos funcionários em relação à disponibilidade e à qualidade da infraestrutura que dão suporte à Cultura de Segurança de Alimentos

Esse construto avalia as percepções dos funcionários em relação à pressão sobre o trabalho envolvendo a manipulação de alimentos e a sua repercussão para obtenção de alimento seguro

m Avalia as percepções sobre a conscientização de riscos organizacionais e as tomadas de decisões relativas a tais riscos em relação à Segurança dos Alimentos

Revista Higiene Alimentar, 36 (294): Jan/Jun, 2022

ISSN 2675-0260 - DOI: 10.37585/HA2022.01cultura 



\begin{tabular}{|c|c|c|c|c|c|}
\hline $\begin{array}{l}\text { De Boeck } \\
\text { et al. } \\
(2015)\end{array}$ & Bélgica & $\begin{array}{l}\text { Indústria de } \\
\text { alimentos }\end{array}$ & $\begin{array}{l}\text { Instrumento de } \\
\text { Clima de Cultura } \\
\text { de Segurança } \\
\text { de Alimentos }\end{array}$ & $\begin{array}{l}\text { (II) Comunicação } \\
\text { (III) Comprometimento } \\
\text { (IV) Recursos } \\
\text { (V) Consciência de risco }\end{array}$ & $\begin{array}{l}\text { Verifica se o líder influencia os liderados a segui-lo, motiva-os a } \\
\text { trabalharem de modo higiênico e seguro, deixa claro quais as } \\
\text { expectativas em relação à Segurança dos Alimentos, escuta os seus } \\
\text { liderados a respeito de melhorias que eles propõem } \\
\text { Baseia-se na qualidade de interações líderes e liderados. Interação } \\
\text { produtiva gera engajamento sobre higiene e Segurança dos } \\
\text { Alimentos. A comunicação deve ser constante, clara, acessível e } \\
\text { compreensível. Cabe à organização criar e promover oportunidades } \\
\text { para melhorar e ampliar os canais de comunicação sobre Segurança } \\
\text { dos Alimentos através de pôsteres, símbolos, ícones, etc.; } \\
\text { Deve partir da liderança, altamente comprometida com a Segurança } \\
\text { dos Alimentos e sendo capaz de contagiar os colaboradores, através } \\
\text { de seu comportamento, atitude e exemplos } \\
\text { Se os funcionários tiverem tempo suficiente para trabalhar de maneira } \\
\text { higiênica e segura, perceberão que há apoio (financeiro, prático, } \\
\text { psicológico e emocional) para questões relacionadas à higiene e à } \\
\text { Segurança dos Alimentos da organização. O número de funcionários } \\
\text { para realizar comportamentos seguros, as condições de trabalho (bom } \\
\text { espaço de trabalho, bons equipamentos e utensílios) e } \\
\text { educação/treinamento em boas práticas também são importantes; } \\
\text { Os colaboradores devem ter conhecimento claro sobre os riscos } \\
\text { relacionados ao trabalho que realizam. Assim se sentirão seguros e }\end{array}$ \\
\hline
\end{tabular}

Previsão de risco: reflete a consciência do risco e a capacidade de priorizar com base na probabilidade de problemas de segurança e qualidade e nas consequências associadas aos mesmos;

Inovação e Mudança: estar pronto para mudança e inovação quando requerido;

Aprendizado Organizacional: A atitude dos indivíduos em relação à aprendizagem organizacional, sua eficácia percebida e seu impacto nos padrões de segurança e qualidade;

Investimento: direcionamento de investimento e cálculo de gastos no orçamento para a segurança e qualidade, e as percepções da eficácia disso trabalharem de modo higiênico e seguro, deixa claro quais as expectativas em relação à Segurança dos Alimentos, escuta os seus de melhorias que eles propõem

produtiva gera Alimentos. A comunicação deve ser constante, clara, acessível e compreensível. Cabe à organização criar e promover oportunidades para melhorar e ampliar os canais de comunicação sobre Segurança dos Alimentos através de pôsteres, símbolos, ícones, etc. de seu comportamento, atitude e exemplos psicológico e emocional) para questões relacionadas à higiene e à Segurança dos Alimentos da organização. O número de funcionários ( educação/treinamento em boas práticas também são importantes; relacionados ao trabalho que realizam. Assim se sentirão seguros e

Revista Higiene Alimentar, 36 (294): Jan/Jun, 2022

ISSN 2675-0260 - DOI: 10.37585/HA2022.01cultura 


\begin{tabular}{|c|c|c|c|}
\hline $\begin{array}{l}\text { Jespersen } \\
\text { et al. } \\
(2016)\end{array}$ & Canadá & $\begin{array}{l}\text { Indústria de } \\
\text { alimentos }\end{array}$ & $\begin{array}{ll}\text { Cultura } & \text { (I) Valor percebido. } \\
\text { organizacional, } & \\
\text { ciência dos } & \text { (II) Sistema de pessoas } \\
\text { alimentos e } & \\
\text { ciência cognitiva } & \\
\text { social } & \end{array}$ \\
\hline
\end{tabular}

confiantes em todo o sistema de gerenciamento de Segurança dos Alimentos da organização. É importante manter atividades que reforçam a importância de conhecer os riscos a autoconfiança de cada um no processo. Os líderes mantêm uma visão realista dos riscos envolvidos e os liderados serão capazes de criar confiança recíproca para tomada de decisões perante problemas reais.

Considera que o investimento em Segurança dos Alimentos leva à melhoria e crescimento contínuo dos negócios

Cabe à direção da organização definir responsabilidades, reconhecendo esta prática como estratégica para o sucesso da Segurança dos Alimentos e o bom desempenho do negócio. Deve também definir ações preventivas e melhoria contínua de ferramentas específicas e comportamentos para e excelência em Segurança dos Alimentos

(III) Pensar sobre os processos A varredura do horizonte e a melhoria contínua são usadas para identificar riscos. A identificação de riscos permite melhorar/aperfeiçoar os planos de mitigação, que estão integrados ao sistema global de gestão de negócios

(IV) Tecnologia ativada Sistemas integrados de gestão são reais e ativos na organização, tornando-a rápida para adaptar, melhorar e usar fluxos de trabalho automatizados e dinâmicos

(V) Ferramentas e infraestrutura O investimento em ferramentas e infraestrutura é avaliado a longo prazo e priorizado junto com outros investimentos de negócios, sempre considerando as necessidades voltadas à Segurança dos Alimentos

\begin{tabular}{llllll}
\hline Global & Colaboração & Toda a cadeia & Cultura & de & (I) Visão e missão. \\
Food & internacional & de alimentos & Segurança & de & \\
Safety & de vários & & Alimentos & & \\
Initiative & países & & & &
\end{tabular}

A liderança organizacional define o tom e a direção de sua Cultura de Segurança de Alimentos. A visão corporativa e as declarações de missão não precisam mencionar especificamente a Segurança dos Alimentos, embora sua importância deva ser refletida nas comunicações da empresa. Ter um direcionamento estabelecido ajuda a construir uma boa Cultura de Segurança de Alimentos, pois esta exige visão clara, compartilhada e incorporada em toda a organização. Este fator é dividido em três subfatores: 1) estrutura do

Revista Higiene Alimentar, 36 (294): Jan/Jun, 2022

ISSN 2675-0260 - DOI: 10.37585/HA2022.01cultura 
(II) Pessoas

(III) Adaptabilidade

(IV) Consistência

(V) Perigos e consciência de risco negócio, valores e propósito; 2) definindo direções e expectativas e 3) liderança e mensagem

As pessoas são um componente crítico para Cultura de Segurança de Alimentos. O comportamento e as atividades dos funcionários, desde os processos na fazenda até o atendimento aos clientes, contribuem para a Segurança dos Alimentos e, potencialmente, diminuem ou aumentam o risco das Doenças Alimentares. É importante estabelecer uma estrutura formal de Segurança dos Alimentos com papéis e responsabilidades claramente definidas. Os principais elementos dessa dimensão incluem desde educar os funcionários e reforçar o bom comportamento até criar uma governança e métricas adequadas. A promoção da SA provoca impacto positivo na capacidade de adaptação, sustentação e melhoria da Cultura de Segurança de Alimentos na organização. Uma boa comunicação garante que as mensagens são compreendidas por todos dentro da organização. Este fator é dividido em cinco subfatores: público-alvo ("stakeholders"); governança; comunicação; aprendizagem organizacional; incentivos, recompensas e reconhecimento

Refere-se a garantir o alinhamento das prioridades de Segurança dos Alimentos com as pessoas, tecnologia, recursos e processos, para aplicar efetivamente um programa de Segurança dos Alimentos e apoiar sua cultura. Este fator é dividido em três subfatores: responsabilidade; mensuração de desempenho; documentação

Capacidade da organização se ajustar às mudanças de influências e condições. Este fator é dividido em três subfatores: expectativas de Segurança dos Alimentos e estado atual; agilidade; mudança, gestão de crises e resolução de problemas

Garantia que todos os trabalhadores conhecem os riscos e consequentemente a responsabilidade como participantes da cadeia produtiva até o consumidor. Cada um tem uma parcela de participação e importância, desde a alta gerência, o executivo sênior até o operador de linha. Este fator é subdividido em três subfatores: educação e

Revista Higiene Alimentar, 36 (294): Jan/Jun, 2022

ISSN 2675-0260 - DOI: 10.37585/HA2022.01cultura 


\begin{tabular}{l}
\hline Nyarugwe \\
et. al. \\
(2016), \\
Nyarugwe \\
et. al. \\
(2018) e \\
Nyarugwe, \\
Linnemann \\
e Luning \\
(2020a)
\end{tabular}

$\begin{array}{ll}\text { Zimbabue } & \begin{array}{l}\text { Indústria de } \\ \text { alimentos } \\ \text { (laticínio) }\end{array} \\ \end{array}$

\section{Cultura \\ Segurança \\ Alimentos}

Cultura Nacional de (I) Características da empresa

e

al (II)

(II) Programa formal Segurança dos Alimentos

(III) Características vulnerabilidade dos produtos

(IV) Características do Processo

(V) Condições favoráveis (condições tecnológicas
organizacionais)

(VI) Características da mão de Atitude: proatividade e engajamento dos trabalhadores no obra (atitude; percepção de cumprimento dos requisitos de segurança e higiene dos alimentos.

risco; percepção de higiene e Percepção de risco: reconhecimento do risco existente na maioria das segurança dos alimentos; e questões de segurança e higiene dos alimentos.

comportamento pretendido)

(VII) Comportamento (comportamento atual controle de higiene e Segurança dos alimentos)

informações fundamentais sobre perigos; engajamento dos funcionários; verificar perigos e consciência de risco

ema a qualidade da força de trabalho (competência em Segurança dos Alimentos) como alta rotatividade de funcionários e a clareza da estrutura organizacional

de Relativo à existência e implementação de um programa formal de Segurança dos Alimentos com base científica, digital, descentralizado, atualizado e validado com base em análises rigorosas por especialistas independentes

Relacionado à probabilidade de contaminação química e microbiológica bem como à sobrevivência e multiplicação de patógenos nos produtos

Relacionado à susceptibilidade de contaminação cruzada

Condições tecnológicas e organizacionais: relacionado à capacidade de gerir os problemas relacionadas à Segurança dos Alimentos

Percepções de higiene e de Segurança dos Alimentos: as percepções dos trabalhadores alinhadas com os requisitos de controle de higiene e Segurança dos Alimentos da empresa.

Comportamento pretendido: comportamento de risco devido à inclinação para se envolver em comportamentos arriscados (ou seja, para cumprir as práticas de controle de higiene e segurança alimentar $\geq 80 \%$ do tempo de trabalho)

tual Comportamento atual de controle de higiene e Segurança dos de Alimentos: risco em relação ao cumprimento total dos requisitos de Segurança dos Alimentos e controle de higiene. Práticas de controle de higiene e Segurança dos Alimentos correta e completamente

Revista Higiene Alimentar, 36 (294): Jan/Jun, 2022

ISSN 2675-0260 - DOI: 10.37585/HA2022.01cultura 



\begin{tabular}{|c|c|c|c|c|c|c|}
\hline $\begin{array}{l}\text { Zanin et. al. } \\
\text { (2021a) }\end{array}$ & Brasil & $\begin{array}{l}\text { Food service } \\
\text { (militar) }\end{array}$ & $\begin{array}{l}\text { Cultura } \\
\text { Segurança } \\
\text { Alimentos }\end{array}$ & $\begin{array}{l}\text { de } \\
\text { de }\end{array}$ & $\begin{array}{l}\text { (I) Liderança. } \\
\text { (II) Comunicação } \\
\text { (III) Conhecimento } \\
\text { (IV) Comprometimento } \\
\text { (V) Percepção de risco } \\
\text { (VI) Pressão de trabalho e } \\
\text { crenças normativas } \\
\text { (VII) Ambiente de trabalho } \\
\text { (VIII) Sistema de gestão, estilo e } \\
\text { processo }\end{array}$ & $\begin{array}{l}\text { Envolvimento dos gestores na Segurança dos Alimentos e garantia } \\
\text { das melhores práticas } \\
\text { Comunicação sobre Segurança dos Alimentos com manipuladores e } \\
\text { como eles se sentem à vontade para falar sobre o tema } \\
\text { Sobre controle de temperatura, contaminação cruzada, higiene } \\
\text { pessoal e alimentar } \\
\text { Satisfação no trabalho e atitudes dos manipuladores } \\
\text { Relacionado ao aparecimento de Doenças Alimentares, letalidade } \\
\text { quando da ingestão de alimentos contaminados e otimismo } \\
\text { inadequado sobre a contaminação dos alimentos } \\
\text { Influência da carga de trabalho em suas práticas e a influência de seus } \\
\text { gerentes, outros manipuladores e autoridades sanitárias } \\
\text { Percepções da capacidade de suporte da estrutura, equipamentos e } \\
\text { utensílios existentes para realizar suas práticas } \\
\text { Percepções sobre os estilos de gestão }\end{array}$ \\
\hline
\end{tabular}

Pressão no trabalho: avalia as percepções dos funcionários frente às pressões no dia a dia de trabalho e como afetam o cumprimento das Boas Práticas.

Julgamento de risco: avalia as percepções dos funcionários sobre a conscientização de risco a nível organizacional; e as decisões individuais que seriam de risco em relação à Segurança dos Alimentos.

Crenças normativas: são as crenças dos indivíduos em relação à influência de outras pessoas que consideram importantes para se decidir quando há necessidade ou não de ter determinados comportamentos específicos

Fonte: GALVÃO e BALIAN. (2021). processo

Revista Higiene Alimentar, 36 (294): Jan/Jun, 2022

ISSN 2675-0260 - DOI: 10.37585/HA2022.01cultura 


\section{DISCUSSÃO}

A presente revisão permitiu afirmar que o conceito de CSA está evoluindo, sendo aprimorado ao longo do tempo, com diferentes abordagens pelos diferentes estudiosos. Após a análise desse conteúdo, concluiu-se que CSA é o conjunto de valores, crenças, atitudes e comportamentos que são praticados frequentemente dentro de uma organização e impactam direta ou indiretamente a segurança dos alimentos ali produzidos e/ou comercializados.

Constatou-se que a temática da CSA é um campo aberto para muitos estudos e avanços ainda a serem revelados. $O$ levantamento aqui apresentado, demonstrou que, no campo da CSA, frequentemente os autores se valeram do apoio de outras áreas do conhecimento e das experiências já acumuladas no campo da gestão organizacional, de forma a facilitar o entendimento sobre quais fatores foram, de fato, mais relevantes e interferentes no processo de construção e direcionamento da CSA nas organizações.

Foram construídos fatores de CSA abordando diferentes elos que estruturaram a cadeia produtiva de alimentos (indústria, "food service", etc.), compondo-se por dois até oito fatores para o diagnóstico ou avaliação da CSA dos estabelecimentos. A finalidade dos autores sempre foi aquela de incrementar e avançar na capacidade de atuarem para a SA, identificando sob quais aspectos de análise do funcionamento da empresa seria possível entender com clareza sobre seus valores, crenças, atitudes e comportamentos direcionados à SA.

O modo de avaliar a CSA foi se alterando ao longo do tempo e autores, passando da aplicação de questionários para o modelo de triangulação ou Metodologia de Avaliação Mista (MAM), nos trabalhos mais recentes (DE ANDRADE et al., 2020; CACCAMO et al., 2018; MANNING, 2018; NYARUGWE, LINNEMANN e LUNING, 2020a; NYARUGWE et al., 2020b; SARTER e SARTER, 2012; WU et al., 2020; ZANIN et al., 2021a; ZANIN et al., 2021b).

A Figura 1 demonstra como a MAM é utilizada para avaliar a CSA, gerando dados que podem melhorar a SA. Essa nova abordagem de avaliação utiliza-se de diferentes fontes de informação para entender o funcionamento da empresa. Em seguida analisa todos os dados de forma sistemática e holística buscando várias interpretações concomitantes para explicar ou caracterizar a CSA existente. Essa temática continua em avanço. Outros autores foram além nas avaliações de CSA e se dedicaram ao desenvolvimento de modelos de maturidade da CSA avaliada (WRIGHT, LEACH e PALMER, 2012; JESPERSEN et al., 2016; 
GLOBAL FOOD SAFETY INITIATIVE, 2018; ZANIN et al., 2021a).

A utilização de instrumentos de avaliação da CSA permitiram à organização entender e identificar os pontos fracos e fortes que dificultam e facilitam, respectivamente, 0 cumprimento das Boas Práticas para a obtenção de alimentos seguros (YIANNAS, 2009; BALL; WILCOCK; COLWELL, 2010; GRIFFITH; LIVESEY; CLAYTON, 2010a;
TAYLOR, 2011). Assim, pode-se desenvolver estratégias de ação para alterar o status da CSA ou administrar aquilo que foi alcançado. A influência da CSA em uma organização é considerável, pois já existem autores que conseguiram verificar que a CSA impacta financeiramente as empresas (JESPERSEN et al., 2019).

Figura 1 - Metodologia de Avaliação Mista da Cultura de Segurança de Alimentos (a). Esquema do funcionamento da Cultura de Segurança de Alimentos utilizando os fatores/elementos de Griffith et al. 2010b (b). Resultado em Segurança dos Alimentos (c). Adaptado de Nyarugwe et al. (2016) e Zanin et al. (2021a).

(a)

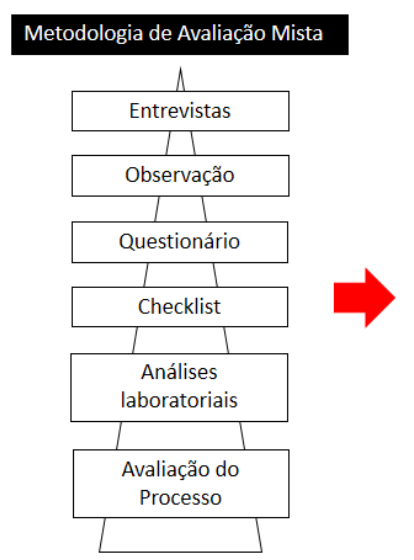

(b)

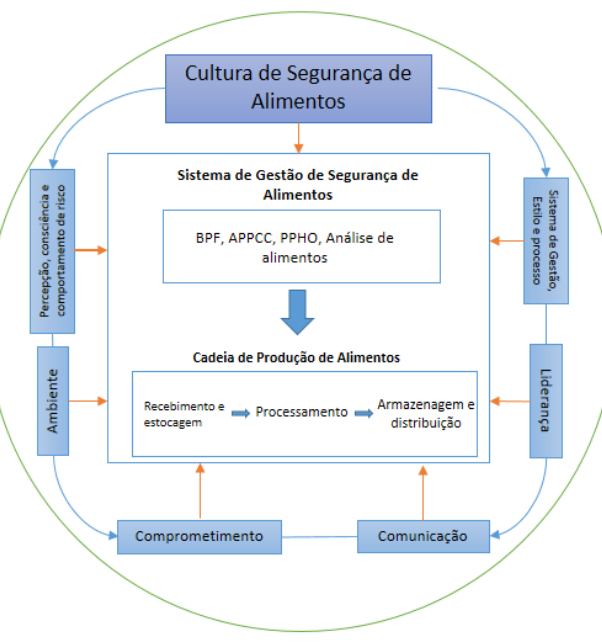

(c)
A maioria dos estudos aqui abordados foi aplicada em grandes empresas. A quantidade de fatores da CSA de cada autor pode ter sido influenciada por isso. Então, durante a aplicação de MAM deve-se levar em consideração tal fato. Novos estudos podem ser desenvolvidos para pequenos estabelecimentos, como por exemplo o realizado por Wright, Leach e Palmer (2012). Outra variável importante abordada 
principalmente por Taylor (2011) e Nyarugwe et al. (2016) foi a Cultura Nacional. Ou seja, cada nação possui uma cultura ou valores que moldam as relações humanas.

No Brasil, existem pesquisadores que se dedicaram ao estudo da CSA, e já validaram instrumentos apresentados nesta revisão e utilizaram instrumentos, por exemplo o questionário, isolados ou em conjunto (ZANIN et al., 2021a; ZANIN et al., 2021b; GALVAO, FERREIRA e BALIAN, 2020; MARTINS, LEITE e BALIAN, 2018). Como a maioria dos estudos de CSA são internacionais, é necessário aproveitá-los para complementar os fatores já descobertos para adaptá-los à cultura brasileira, visto que o Brasil é um país continental e diverso. Com isso, a formulação de um fator como a localização da empresa dentro de um conjunto de fatores de CSA auxiliaria uma futura pesquisa a caracterizar com mais precisão a CSA de acordo com as características locais de uma organização no Brasil.

$\mathrm{Na}$ literatura nacional e internacional estão disponíveis vários outros trabalhos relacionados à CSA, tais como (GALVÃO, FERREIRA e BALIAN, 2020; WU et al., 2020; WIŚNIEWSKA, CZERNYSZEWICZ, e KAŁUŻA, 2019; MARTINS, LEITE e BALIAN 2018; CACCAMO et al., 2018; EMOND e TAYLOR, 2018; NOUAIMEH et al., 2018; TAYLOR e BUDWORTH, 2018; TAYLOR e
ROSTRON, 2018), porém, como estes não se dedicaram a propor novos fatores ou elementos relativos à CSA, não foram considerados no levantamento discutido no presente artigo.

\section{CONCLUSÃO}

A CSA é um campo da ciência em plena expansão e com oportunidades para se descobrir novos resultados. Mostrou-se nesta revisão os conceitos de CSA encontrados na literatura. Foi proposto pelos autores desta pesquisa a definição de CSA como sendo o conjunto de valores, crenças, atitudes e comportamentos que são praticados frequentemente dentro de uma organização e impactam direta ou indiretamente a segurança dos alimentos ali produzidos e/ou comercializados.

Foram encontrados dezoito trabalhos que apresentaram diferentes fatores de CSA. Além disso, foram identificados quatro trabalhos que aplicaram instrumentos de CSA no Brasil.

A utilização de ferramentas para caracterizar a CSA foi se aprimorando ao longo do tempo. Os autores mais recentes frequentemente utilizam uma abordagem mista de métodos de avaliação para tal finalidade.

Percebeu-se uma semelhança entre alguns fatores nos trabalhos apresentados, demonstrando que é um fenômeno que se 
repete na realidade das organizações. Propõem-se que o fator localização da empresa seja considerado para caracterizar a CSA no Brasil, já que é um país continental com culturas diversas.

A mensuração da CSA é importante, pois pode impactar os resultados em SA. Gerar novas estratégias de ação a partir dos resultados encontrados após a caracterização da CSA é fundamental para iniciar e administrar o controle sobre SA.

A apresentação e organização desses trabalhos divulgados nesta revisão estimulará a comunidade científica a se debruçar sobre o assunto. Assim, pode-se aprimorar ou construir novos fatores de CSA para encontrar resultados que ajudem a formar uma CSA positiva para a SA nas organizações.

\section{REFERÊNCIAS}

ABIDIN, U. F. U. Z. Measuring food safety culture: insights from onsite foodservice operations. 2013. 186 f. Dissertação (Doutor em Filosofia) - lowa State University, 2013. lowa, 2013.

BALL, B.; WILCOCK, A.; COLWELL, S. Tool For Measuring Food Safety Climate. Journal of Food Protection, United States, v. 73, p. 84, Jan. de 2010.

BRASIL. Ministério da Saúde. Secretaria de Vigilância em Saúde. Departamento de Vigilância das Doenças Transmissíveis. Coordenação Geral de Doenças Transmissíveis. Surtos de Doenças Transmitidas por Alimentos no Brasil - Informe 2018. Ministério da Saúde, 2019. Disponível em:
$<$ https://antigo.saude.gov.br/images/pdf/2019 /maio/17/Apresentacao-Surtos-DTA-Maio2019.pdf>. Acesso em: 08 mar. 2021.

CACCAMO, A.; TAYLOR, J. Z.; DANIEL, D.; BULATOVIC-SCHUMER, R. Measuring and improving food safety culture in a five-star hotel: a case study. Worldwide Hospitality and Tourism Themes, United Kingdon, v. 10, n. 3, p. 345-357, 2018. Disponível em: <https://doi.org/10.1108/WHATT-02-20180010>. Acesso em 10 fev. 2021.

CENTERS FOR DISEASE CONTROL (CDC). Surveillance for foodborne disease outbreaks United States, 2017: Annual report. CDC, $2017 . \quad$ Disponível em: <https://www.cdc.gov/fdoss/pdf/2017_FoodB orneOutbreaks_508.pdf >.Acesso em: 08 mar. 2021.

DE ANDRADE, M. L.; STEDEFELDT, E.; ZANIN, L. M.; DA CUNHA, D. T. Food safety culture in food services with different degrees of risk for foodborne diseases in Brazil. Food Control, United States, v. 112, 2020. Disponível em: <https://doi.org/10.1016/j.foodcont.2020.1071 52>. Acesso em: 10 fev. 2021.

DE BOECK, E.; JACXSENS, L.; BOLLAERTS, M.; VLERICK, P. Food safety climate in food processing organizations: development and validation of a selfassessment tool. Trends in Food Science \& Technology, United States, 29 Set. de 2015. v. 46 , n. 2, p. 242-251, 2015. Disponível em: <http://dx.doi.org/10.1016/j.tifs.2015.09.006>. Acesso em: 10 jun. 2017.

EMOND, B.; TAYLOR, J. Z. The importance of measuring food safety and quality culture: results from a global training survey. Worldwide Hospitality and Tourism Themes, United Kingdon, v. 10 n. 3, p. 369375, 2018. Disponível em: <https://doi.org/10.1108/WHATT-02-20180012>. Acesso em: 10 fev. 2021. 
EUROPEAN FOOD SAFETY AUTHORITY (EFSA). The European Union summary report on trends and sources of zoonoses, zoonotic agents and food-borne outbreaks in 2017. EFSA Journal, European Union, v. 16, n.12, p. 262, 2018. Disponível em: <https://doi.org/10.2903/j.efsa.2018.5500>.

Acesso em: 08 mar. 2021.

FUJISAKI, K.; AKAMATSU, R. Food safety culture assessment scale development and validation for use in school foodservice. British Food Journal, United Kingdon, v. 122, n. 3, p. 737-752, 2020. Disponível em: <https://doi.org/10.1108/BFJ-04-2019-0280>. Acesso em 10 fev. 2021.

GALVÃO, V. C.; FERREIRA, W. L. do M.; BALIAN, S. de C. Adaptação e validação de instrumento para caracterização de cultura de segurança de alimentos, Revista Higiene Alimentar, Brasil, v. 34, n. 290, 2020. Disponível em: https://doi.org/10.37585/HA2020.adaptacao. Acesso em: 20 Jan. 2021.

GLOBAL FOOD SAFETY INITIATIVE (GFSI) A culture of food safety: a position paper from the global food safety initiative. France, FR: 2018. p. 54.

GRIFFITH, C. P. Food safety: where from and where to?, British Food Journal, United Kingdom, v. 108, n. 1, pp.6-15, 2006. Disponível em: <https://doi.org/ 10.1108/00070700610637599>. Acesso em: 20 Jan. 2021.

GRIFFITH, C. J.; LIVESEY, K. M.; CLAYTON, D. A. Food safety culture: the evolution of an emerging risk factor? British Food Journal, United Kingdom, v. 112, n. 4, pp.426-438, 2010a. Disponível em: <https://doi.org/10.1108/0007070101103443 9>. Acesso em: 20 Jan. 2021.

GRIFFITH, C. J.; LIVESEY, K. M.; CLAYTON, $D$. A. The assessment of food safety culture. British Food Journal, United Kingdom, v. 112, n. 4, p. 439-456, 2010b. Disponível em: <https://doi.org/10.1108/0007070101103444 8>. Acesso em: 22 Mai. 2017.

JESPERSEN, L.; GRIFFITHS, M.; MACLAURIN, T.; CHAPMAN, B.; WALLACE, C. A. Measurement of Food Safety Culture using Survey and Maturity Profiling Tools. Food Control, United States, v. 66, p. 174182, 2016. Disponível em: $<$ http://dx.doi.org/10.1016/j.foodcont.2016.01. 030>. Acesso em: 21 jun. 2017.

JESPERSEN, L.; BUTTS, J.; HOLLER, G.; TAYLOR, J.; HARLAN, D.; GRIFFITHS, M.; WALLACE, C. A. The impact of maturing food safety culture and a pathway to economic gain. Food Control, United States, v. 98, p. 367-379, 2019. Disponível em: <https://doi.org/10.1016/j.foodcont.2018.11.0 41>. Acesso em 10 fev. 2021.

MANNING, L. Triangulation: Effective verification of food safety and quality management systems and associated organisational culture. Worldwide Hospitality and Tourism Themes, United Kingdon, v. 10, n. 3, p. 297-312, 2018. Disponível em: <https://doi.org/10.1108/WHATT-02-20180009>. Acesso em 10 fev. 2021.

MARTINS, W. S.; LEITE, A. B. de C.; BALIAN, $S$. de C. Translation into Portuguese, adaptation, and validity assessment of the food safety climate self-assessment tool, Journal of Food Safety, United States, v. 38, n. 6, pp. 1-10, 2018. Disponível em: < https://doi.org/10.1111/jfs.12552>. Acesso em: 20 Jan. 2021.

NEAL, J. A.; BINKLEY, M.; HENROID, D. Assessing factors contributing to food safety culture in retail food establishments. Food Protection Trends, United States, Ago. 2012. v. 32, n. 8, p. 468-476, 2012.

NOUAIMEH, N.; PAZHANTHOTTA, R. T.; TAYLOR, J. Z.; BULATOVIC-SCHUMER, R. Measuring and improving food safety culture in a large catering company: a case study. 
Worldwide Hospitality and Tourism Themes, United Kingdon, v. 10, n. 3, p. 358368, 2018. Disponível em: $<$ https://doi.org/10.1108/WHATT-02-20180011>. Acesso em: 10 fev. 2021.

NYARUGWE, S. P.; LINNEMANN, A.; HOFSTEDE, G. J.; FOGLIANO, V.; LUNING, $P$. A. Determinants for conducting food safety culture research. Trends in Food Science \& Technology, United States, v. 56, p. 77-87, $2016 . \quad$ Disponível em: <http://dx.doi.org/10.1016/j.tifs.2016.07.015>. Acesso em: 10 fev. 2021.

NYARUGWE, S. P.; LINNEMANN, A.; NAYANGA, L. K.; FOGLIANO, V.; LUNING, P. A. Food safety culture assessment using a comprehensive mixed-methods approach: a comparative study in dairy processing organisations in an emerging economy. Food control, United States, v. 84, p. 186-196, $2018 . \quad$ Disponível em: <http://dx.doi.org/10.1016/j.foodcont.2017.07. 038>. Acesso em: 20 Jan. 2021.

NYARUGWE, S. P.; LINNEMANN, A. R.; LUNING, P. A. Prevailing food safety culture in companies operating in a transition economy - Does product riskiness matter? Food Control, United States, v. 107, 2020a. Disponível em: <https://doi.org/10.1016/j.foodcont.2019.1068 03>. Acesso em: 10 fev. 2021.

NYARUGWE, S. P.; LINNEMANN, A. R.; REN, Y.; BAKKER, E.; KUSSAGA, J. B.; WATSON, D.; FOGLIANO, V.; LUNING, P. A. An intercontinental analysis of food safety culture in view of food safety governance and national values. Food Control, United States, v. 111, 2020b. Disponível em: <https://doi.org/10.1016/j.foodcont.2019.1070 75>. Acesso em: 10 fev. 2021.

SARTER. G.; SARTER, S. Promoting a culture of food safety to improve hygiene in small restaurants in Madagascar. Food Control, United States, v. 25, p. 165-171, 2012.

$$
\text { Disponível }
$$

em: <https://doi.org/10.1016/j.foodcont.2011.10.0 23>. Acesso em: 10 fev. 2021.

SEWARD, S.; DOBMEIER, N.; BARON, M. Assessing the food safety culture of a manufacturing facility. Institute of Food Technololy. United States, v. 66, n. 1, p. 4447, 2012. Disponível em: <http://www.ift.org/Food-Technology/PastIssues/2012/January.aspx>. Acesso em: 27 Set. 2018.

SHARMAN, N.; WALLACE, C.A.; JESPERSEN, L. Terminology and the understanding of culture, climate, and behavioural change - Impact of organisational and human factors on food safety management. Trends in Food Science \& Technology, United States, v. 96, p. 13-20, $2020 . \quad$ Disponível em: <https://doi.org/10.1016/j.tifs.2019.12.005>.

Acesso em: 10 fev. 2021.

POWELL, D. A.; JACOB, C. J.; CHAPMAN, B. $J$. Enhancing food safety culture to reduce rates of foodborne illness. Food Control, United States, v. 22, p. 817-822, 2011. Disponível em: <https://doi.org/10.1016/j.foodcont.2010.12.0 09>. Acesso em 10 mar. 2021.

TAYLOR, J. Z. An exploration of food safety culture in a multi-cultural environment: next steps? Worldwide Hospitality and Tourism Themes, United Kindom, v. 3, n. 5, p. 455466, 2011. Disponível em: < https://www.emeraldinsight.com/doi/full/10.11 08/17554211111185836>. Acesso em: 20 Jan. 2017.

TAYLOR, J. Z.; BUDWORTH, L. Patterns and trends from a quantitative analysis of the Culture Excellence assessment program. Worldwide Hospitality and Tourism Themes, United Kingdon, v. 10 n. 3, p. 330344, 2018. Disponível em: <https://doi.org/10.1108/WHATT-02-20180007>. Acesso em: 10 fev. 2021. 
TAYLOR, J. Z.; ROSTRON, K. I. The development of a safety and quality culture assessment tool from a longitudinal, mixedmethod research journey. Worldwide Hospitality and Tourism Themes, United Kingdon, v. 10, n. 3, p.313-329, 2018. Disponível em: <https://doi.org/10.1108/WHATT-02-20180006 >. Acesso em: 10 fev. 2021.

TAYLOR, J. Z.; GARAT, J. P.; SIMREEN, S.; SARIEDDINE, G. An industry perspective: a new model of food safety culture excellence and the impact of audit on food safety standards. Worldwide Hospitality and Tourism Themes, United Kindom, v. 7, n. 1, p. 78-89, 2015. Disponível em: <https://www.emeraldinsight.com/doi/full/10.1 108/WHATT-12-2014-0041>. Acesso em: 10 fev. 2021.

WIŚNIEWSKA, M.; CZERNYSZEWICZ, E.; KAŁUŻA, A. The assessment of food safety culture in small franchise restaurant in Poland: The case study. British Food Journal, United Kingdon, v. 121, n. 10, p. 2365-2378, 2019. Disponível em: <https://doi.org/10.1108/BFJ03-2019-0152>. Acesso em: 10 fev. 2021.

WRIGHT, A. M. S.; LEACH, P.; PALMER, G. A tool to diagnose culture in food business operators: report from greenstreet berman Itd. for the Food Standards Agency. Boston: Greenstreet Berman Ltd, 2012. p. 1-110.

WU, S. T.; HAMMONS, S. R.; SILVER, R.; NEAL, J. A.; OLIVER, H. F. Retail deli managers and associates have better food safety culture in stores with lower Listeria monocytogenes contamination. Food Control, United States, v. 110, 2020. Disponível em: <https://doi.org/10.1016/j.foodcont.2019.1069 83>. Acesso em: 10 fev. 2021.

YIANNAS, F. Food safety culture: creating a behavior-based food safety management system. New York: Springer-Verlag, 2009. p. 96. eBook ISBN: 978-0-387-72867-4.
ZANIN, L. M.; LUNING, P. A.; DA CUNHA, D. T.; STEDEFELDT, E. Influence of educational actions on transitioning of food safety culture in a food service context: Part 1 Triangulation and data interpretation of food safety culture elements. Food Control, United States, v. 119, 2021a. Disponível em: <https://doi.org/10.1016/j.foodcont.2020.1074 47>. Acesso em: 10 fev. 2021.

ZANIN, L. M.; STEDEFELDT, E.; DA SILVA, S. M.; DA CUNHA, D. T.; LUNING, P. A. Influence of educational actions on transitioning of food safety culture in a food service context: Part 2 - Effectiveness of educational actions in a longitudinal study. Food Control, United States, v. 120, 2021b. Disponível em: <https://doi.org/10.1016/j.foodcont.2020.1075 42>. Acesso em: 10 fev. 2021. 